Published in final edited form as:

Ann Surg Oncol. 2018 June ; 25(6): 1488-1494. doi:10.1245/s10434-018-6429-2.

\title{
Is Low-Volume Disease in the Sentinel Node After Neoadjuvant Chemotherapy an Indication for Axillary Dissection?
}

\author{
Tracy-Ann Moo, MD², Marcia Edelweiss, MD², Sabina Hajiyeva, MD², Michele Stempel, \\ MPH $^{1}$, Monica Raiss, BA ${ }^{1}$, Emily C. Zabor, MS $^{3}$, Andrea Barrio, MD ${ }^{1}$, and Monica Morrow, \\ MD ${ }^{1}$ \\ ${ }^{1}$ Breast Service, Department of Surgery, Memorial Sloan Kettering Cancer Center, New York, NY \\ ${ }^{2}$ Department of Pathology, Memorial Sloan Kettering Cancer Center, New York, NY \\ ${ }^{3}$ Department of Epidemiology and Biostatistics, Memorial Sloan Kettering Cancer Center, New \\ York, NY
}

\section{Abstract}

Background/Objective-Intraoperative evaluation of sentinel lymph nodes (SLNs) after neoadjuvant chemotherapy (NAC) has a higher false-negative (FN) rate than in the primary surgical setting, particularly for small tumor deposits. Additional tumor burden seen with isolated tumor cells (ITCs) and micrometastases following primary surgery is low. It is unknown whether the same is true after NAC. We examined the FN rate of intraoperative frozen section (FS) after NAC, and the association between SLN metastasis size and residual disease at axillary dissection (ALND).

Methods-Patients undergoing SLN biopsy after NAC were identified. The association between SLN metastasis size and residual axillary disease was examined.

Results-From July 2008-July 2017702 patients (711 cancers) had SLN biopsy after NAC. On FS, 181 had metastases, 530 were negative; 33 negative cases were positive on final pathology (FN rate $6.2 \%)$. Among patients with a positive FS, 3 (2\%) had ITCs and no further disease on ALND. $41(23 \%)$ had micrometastases and $125(69 \%)$ macrometastases. 59\% with micrometastases and $63 \%$ with macrometastases had $\geq 1$ additional positive node at ALND. Among those with a FN result, $10(30 \%)$ had ITC, $15(46 \%)$ micrometastases and 8 (24\%) macrometastases. 17 had ALND and 59\% had $\geq 1$ additional positive lymph node. Overall, 1/6 (17\%) patients with ITC and 28/44 (64\%) with micrometastases had additional nodal metastases at ALND.

Conclusion-Low-volume SLN disease after NAC is not an indicator of a low risk of additional positive axillary nodes and is an indication for ALND, even when not detected on intraoperative FS.

\footnotetext{
Corresponding author: Monica Morrow, MD, Breast Service, Department of Surgery, Memorial Sloan Kettering Cancer Center, 300 East 66th Street, New York, NY 10065, (T) 646888 5350, (F) 646888 5365, morrowm@mskcc.org.

This study has been accepted for presentation at the 2018 Society of Surgical Oncology Annual Cancer Symposium, March 21-24, 2018, Chicago, IL.

The authors have no conflict of interest disclosures to report.
} 


\section{Keywords}

sentinel lymph node; neoadjuvant chemotherapy; breast cancer; intraoperative frozen section; sentinel lymph node biopsy; non-sentinel node metastases

\section{INTRODUCTION}

In the setting of primary surgery for breast cancer, volume of disease in the sentinel lymph node (SLN) is an important predictor of the likelihood of additional non-sentinel lymph node (NSLN) metastases. ${ }^{1-5}$ Patients with low-volume SLN disease, defined as micrometastases or isolated tumor cells (ITCs), have a risk of additional NSLN metastases of approximately $10-20 \% .^{4,6-9}$ In patients who undergo sentinel lymph node biopsy (SLNB) after neoadjuvant chemotherapy (NAC), the correlation between volume of disease in the sentinel node and the likelihood of additional positive NSLN is unknown. The relationship between volume of disease in the SLN and residual NSLN metastases is particularly relevant in cases where an intraoperative assessment of the sentinel node is falsely negative, and a return to the operating room for axillary dissection (ALND) is considered standard. The sensitivity of intraoperative frozen section (FS) of the SLN after NAC has been reported in small studies to range from $67-81 \% .{ }^{10-13}$ As is the case in primary SLN surgery, intraoperative FS in the neoadjuvant setting has a lower sensitivity for detecting micrometastasis or ITCs than for detecting macrometastases. ${ }^{11,14}$ Whether or not the failure to detect tumor deposits on FS indicates a low risk of residual axillary disease has not been studied. The purpose of this study was to determine the sensitivity of intraoperative FS of the SLN after NAC in a large, contemporary group of patients and to examine the association between volume of disease in the SLN and the probability of finding additional positive NSLN at completion axillary dissection.

\section{METHODS}

This study was approved by the Memorial Sloan Kettering Cancer Center Institutional Review Board. All breast cancer patients who had NAC followed by a SLNB with intraoperative FS between July 2008 and July 2017 were identified from a prospectively maintained database. Demographic, clinical, pathologic, and treatment data were examined. Axillary lymph node metastasis size was classified as ITC, micrometastases, and macrometastasis based on the American Joint Committee on Cancer $7^{\text {th }}$ Edition breast cancer staging guidelines. ${ }^{15}$ SLN metastases measuring $\leq 0.2 \mathrm{~mm}$ or 200 tumor cells were classified as ITC, metastases greater than $0.2 \mathrm{~mm}$ to $\leq 2 \mathrm{~mm}$ as micrometastases, and those $>2 \mathrm{~mm}$ as macrometastasis.

Axillary sentinel node mapping was performed with single or dual tracers. Technetium sulfur colloid and/or isosulfan blue were used in patients who were clinically node negative prior to NAC according to surgeon preference. The use of dual tracers was mandatory in patients initially clinically node positive prior to NAC. Intraoperative FS examination was routinely performed. Sentinel lymph nodes received for intraoperative assessment were cut into $2 \mathrm{~mm}$ thick sections along the major axis of the lymph node. All lymph node slices were frozen, and histological hematoxylin and eosin $(\mathrm{H} \& \mathrm{E})$ stained slides were prepared for 
microscopic examination. In general, a single slide was examined during frozen section. Intraoperatively, the SLNs were reported as negative for carcinoma, positive, or the diagnosis was deferred to permanent section in cases where evaluation was not definitive. For final histopathological evaluation and reporting, formalin-fixed, paraffin-embedded H\&E slides were evaluated for each SLN that had been frozen. Only selected cases, such as those with a few suspicious cells, treatment effect, or crush/processing artifact, had more than one level H\&E slide ordered and/or immunohistochemical staining for cytokeratin AE1-AE3.

Intraoperative FS results were deemed false negative if the intraoperative FS was reported as negative or the diagnosis was deferred and the permanent section was subsequently positive for metastases of any size. Deferred cases were included as false negatives since an intraoperative management decision could not be made based on FS results. ITCs detected on either FS or subsequent H\&E or IHC were considered positive. The false-negative rate and sensitivity of intraoperative FS were calculated using the total number of negative FS results as the denominator.

Patient and tumor characteristics were summarized as the median (minimum, maximum) for continuous variables and as the frequency $(\%)$ for categorical variables. The Kruskal-Wallis test and Fisher's exact test were used for between-group comparisons for continuous and categorical variables, respectively. A p-value $<0.05$ was considered statistically significant. All statistical analyses were conducted in R version 3.4.1 (R Core Development Team, Vienna, Austria).

\section{RESULTS}

A total of 702 patients (711 cancers) who underwent SLNB with intraoperative FS after NAC were identified. All patients had clinical stage II-III disease, 360 cancers were clinically node negative, and 351 were clinically node positive prior to NAC. Of 351 patients with clinically positive nodes, 291 were histologically confirmed. All patients were clinically node negative by physical examination following chemotherapy. On intraoperative FS, 181 cases were positive for SLN metastases, 522 were negative, and 8 (1.1\%) were deferred. Of 530 negative or deferred cases, 33 were positive on permanent section, an overall false-negative rate of $6.2 \%$. Five of the 33 false-negative cases were cases in which the diagnosis was deferred at intraoperative FS. There were no false-positive FS results in this study.

Demographic, clinical, pathologic, and treatment characteristics of the 181 patients with positive frozen sections (FS+) and the 33 with false-negative FS are shown in Table 1. Patients with a FS-false negative result were more likely to have had clinically negative nodes prior to NAC $(\mathrm{p}=0.004)$ and no evidence of lymphovascular invasion $(\mathrm{p}=0.04)$. Patients with a FS+ result were significantly more likely to have macrometastases (69\%) compared to those with a FS-false negative result, who were more likely to have a micrometastasis $(45.5 \%)$ or ITCs $(30 \%)(\mathrm{p}<0.001)$ (Fig. 1). All patients with a FS+ result underwent ALND at the initial operation except 15 who were randomized to the no-ALND arm of the Alliance A11202 trial. Of the patients with a FS-false negative result, 17/33 
(52\%) subsequently had an ALND and 16 had no further surgery and received nodal irradiation. Among the 16 patients who did not undergo ALND, 8 had ITCs, 6 had micrometastasis, and 2 had macrometastasis; 8 patients (micrometastasis and macrometastasis) eligible for the Alliance A11202 trial declined enrollment.

Overall, among all patients with a positive sentinel node irrespective of method of detection, $1 / 6(17 \%)$ of those with ITCs, 28/44 (64\%) with micrometastases, and 75/121 (62\%) with macrometastasis had additional NSLN metastases identified at ALND (Fig. 2). Of the 44 patients with SLN micrometastases, 34\% (15/44) had $\geq 2$ positive NSLNs (range 2-8), and a third of all NSLN metastases were macrometastases. Among the patients who were FS+, 3 had ITCs and no further disease found at ALND. Of FS+ patients with micrometastases and macrometastases, $59 \%$ and $63 \%$, respectively, had $\geq 1$ additional positive NSLN at ALND. Patients with SLN macrometastasis had greater numbers of additional positive nodes, ranging from 1-15 nodes compared to 1-8 additional involved nodes in patients with SLN micrometastases $(\mathrm{p}=0.03)$ (Table 2). Among those with a FS-false negative result who underwent ALND, 1 patient with ITCs had $>3$ additional positive NSLNs, and 85\% (6/7) of patients with micrometastases and $43 \%$ (3/7) with macrometastasis had $\geq 1$ additional positive NSLN.

\section{DISCUSSION}

In patients undergoing primary surgery, axillary recurrence is uncommon when micrometastases and macrometastases in the sentinel nodes are managed without axillary dissection. ${ }^{16,17}$ It is unclear whether these results can be safely extrapolated to patients treated with NAC where residual nodal disease in the axilla potentially represents a population of tumor cells resistant to chemotherapy. In addition, a micrometastases in a node post-NAC may be a small tumor deposit with a relatively low risk of additional nodal disease, or could be residual disease from a macrometastases with a heavier residual tumor burden. The current standard of care for management of any viable tumor cells in the SLN after neoadjuvant therapy is ALND. ${ }^{18}$ The increasing use of SLN biopsy to stage the axilla following NAC raises the question of whether or not low-volume residual disease in the SLN mandates ALND. Intraoperative examination of the SLN is a valuable tool to identify nodal metastasis at the time of surgery, but false-negative results are more common after neoadjuvant therapy than in the primary surgical setting. ${ }^{10,19}$ Our results demonstrate a sensitivity for intraoperative FS of $93.8 \%$, higher than reported in prior studies, half of which routinely used IHC and reported sensitivities ranging from $67-81 \%{ }^{10,12,13,20}$ At our institution, routine IHC is not performed for sentinel node evaluation, and this practice may have lowered the false-negative rate. Among the 33 patients with a false-negative intraoperative FS result, 76\% had ITCs or micrometastases. This is consistent with previous studies demonstrating that low-volume disease is more likely to be missed on FS. ${ }^{11}$

Reported rates of NSLN positivity in patients found to have SLN metastases after NAC range from approximately $50-70 \%$, substantially higher than those reported in patients with positive SLNs randomized to ALND in ACOSOG Z0011 or AMAROS. ${ }^{17,21-24}$ Jeruss et al examined 104 patients undergoing NAC and found a rate of NSLN positivity of $47 \%$ and $71 \%$, respectively, for patients who were clinically node negative vs. node positive at 
presentation. ${ }^{23}$ Similarly, Galimberti et al, in an analysis of 396 patients undergoing NAC followed by SLNB, found that among patients who were clinically node positive at presentation, $71.5 \%$ of those with a positive SLN had additional NSLN metastasis. ${ }^{22}$ Although these studies illustrate that rates of NSLN positivity are high after NAC, neither study examined the correlation between SLN metastasis size and probability of NSLN involvement. We found that patients with ITCs and micrometastases in the SLN had rates of $17 \%$ and $64 \%$ NSLN positivity, respectively, substantially higher than the $12 \%$ with ITCs and $20 \%$ with micrometastases reported in the primary surgical setting. ${ }^{4,6,9}$ While ITCs appear to have a lower probability of being associated with positive NSLN, our small numbers limit conclusions regarding their relationship to residual axillary disease. In contrast, patients with micrometastasis in the SLN had a tumor burden very similar to patients with macrometastasis, with $64 \%$ and $62 \%$, respectively, having $\geq 1$ positive NSLN.

All patients in this study not enrolled in a clinical trial who had a metastases identified on FS had an immediate completion ALND, while only half of those with a false-negative FS result were returned to the operating room for completion ALND. These findings mirror the nationwide trend of omitting ALND for positive SLNs after NAC. Kantor et al, in a National Cancer Database study of 12,063 patients treated between 2006 and 2013, demonstrated that following the reporting of the results of the ACOSOG Z11 trial in 2010, 26\% of patients with positive sentinel nodes after NAC did not receive a completion ALND. ${ }^{25}$ Although the ACOSOG Z11 trial demonstrated no difference in recurrence or survival in patients undergoing breast conservation who had 2 or fewer positive sentinel nodes and were randomized to ALND or no further surgery, ${ }^{17,26}$ the study did not include patients who had NAC. Similarly, in patients undergoing primary surgery, the IBCSG 23-01 trial showed that omission of ALND with low-volume SLN disease does not decrease survival or increase local recurrence, ${ }^{16}$ and the AMAROS trial demonstrated equivalence of nodal irradiation to ALND for positive sentinel nodes in clinically node-negative breast cancer. ${ }^{21}$ Our study suggests that the tumor burden associated with a positive sentinel node after NAC is substantially higher than was present in these studies. Until outcome data demonstrate that elimination of ALND is safe, it should remain the standard of care, even when only micrometastatic disease is present. We also found that the failure to identify nodal metastases on FS is not necessarily indicative of a low residual tumor burden and should not be used as a rationale for avoiding ALND.

Strengths of this study include a large population of patients treated in a relatively recent time period and a high rate of completion ALND. A limitation of this study is that intraoperative assessment methods differ among institutions, and the low false-negative rate seen here may not be applicable in institutions where IHC is routinely performed, as this could potentially influence rates of residual disease in NSLNs. Additionally, the number of patients with ITCs in this study was low and limits conclusions regarding residual axillary disease in this group.

\section{Conclusions}

Low-volume disease in the SLN after NAC detected on either intraoperative FS or permanent section is not an indicator of a low risk of additional positive axillary nodes. As 
the implications of leaving chemotherapy-resistant tumor cells in the axilla are unclear, detection of these cells in the SLN remains an indication for ALND.

\section{Acknowledgments}

The preparation of this study was funded in part by NIH/NCI Cancer Center Support Grant No. P30 CA008748 to Memorial Sloan Kettering Cancer Center.

\section{References}

1. Chu KU, Turner RR, Hansen NM, Brennan MB, Bilchik A, Giuliano AE. Do all patients with sentinel node metastasis from breast carcinoma need complete axillary node dissection? Ann Surg. 1999; 229(4):536-41. [PubMed: 10203087]

2. Turner RR, Chu KU, Qi K, Botnick LE, Hansen NM, Glass EC, Giuliano AE. Pathologic features associated with nonsentinel lymph node metastases in patients with metastatic breast carcinoma in a sentinel lymph node. Cancer. 2000; 89(3):574-81. [PubMed: 10931456]

3. Kamath VJ, Giuliano R, Dauway EL, Cantor A, Berman C, Ku NN, Cox CE, et al. Characteristics of the sentinel lymph node in breast cancer predict further involvement of higher-echelon nodes in the axilla: a study to evaluate the need for complete axillary lymph node dissection. Arch Surg. 2001; 136(6):688-92. [PubMed: 11387010]

4. Cserni G, Gregori D, Merletti F, Sapino A, Mano MP, Ponti A, Sandrucci S, et al. Meta-analysis of non-sentinel node metastases associated with micrometastatic sentinel nodes in breast cancer. $\mathrm{Br} \mathbf{J}$ Surg. 2004; 91(10):1245-52. [PubMed: 15376203]

5. Viale G, Maiorano E, Pruneri G, Mastropasqua MG, Valentini S, Galimberti V, Zurrida S, et al. Predicting the risk for additional axillary metastases in patients with breast carcinoma and positive sentinel lymph node biopsy. Ann Surg. 2005; 241(2):319-25. [PubMed: 15650643]

6. van Deurzen CH, de Boer M, Monninkhof EM, Bult P, van der Wall E, Tjan-Heijnen VC, van Diest PJ. Non-sentinel lymph node metastases associated with isolated breast cancer cells in the sentinel node. J Natl Cancer Inst. 2008; 100(22):1574-80. [PubMed: 19001602]

7. Houvenaeghel G, Nos C, Giard S, Mignotte H, Esterni B, Jacquemier J, Buttarelli M, et al. A nomogram predictive of non-sentinel lymph node involvement in breast cancer patients with a sentinel lymph node micrometastasis. Eur J Surg Oncol. 2009; 35(7):690-5. [PubMed: 19046847]

8. Van Zee KJ, Manasseh DM, Bevilacqua JL, Boolbol SK, Fey JV, Tan LK, Borgen PI, et al. A nomogram for predicting the likelihood of additional nodal metastases in breast cancer patients with a positive sentinel node biopsy. Ann Surg Oncol. 2003; 10(10):1140-51. [PubMed: 14654469]

9. Kumar S, Bramlage M, Jacks LM, Goldberg JI, Patil SM, Giri DD, Van Zee KJ. Minimal disease in the sentinel lymph node: how to best measure sentinel node micrometastases to predict risk of additional non-sentinel lymph node disease. Ann Surg Oncol. 2010; 17(11):2909-19. [PubMed: 20532987]

10. Akay CL, Albarracin C, Torstenson T, Bassett R, Mittendorf EA, Yi M, Kuerer HM, et al. Factors impacting the accuracy of intra-operative evaluation of sentinel lymph nodes in breast cancer. Breast J. 2017

11. Rubio IT, Aznar F, Lirola J, Peg V, Xercavins J. Intraoperative assessment of sentinel lymph nodes after neoadjuvant chemotherapy in patients with breast cancer. Ann Surg Oncol. 2010; 17(1):2359. [PubMed: 19777186]

12. Komenaka IK, Torabi R, Nair G, Jayaram L, Hsu CH, Bouton ME, Dave H, et al. Intraoperative touch imprint and frozen section analysis of sentinel lymph nodes after neoadjuvant chemotherapy for breast cancer. Ann Surg. 2010; 251(2):319-22. [PubMed: 19864940]

13. Shimazu K, Tamaki Y, Taguchi T, Tsukamoto F, Kasugai T, Noguchi S. Intraoperative frozen section analysis of sentinel lymph node in breast cancer patients treated with neoadjuvant chemotherapy. Ann Surg Oncol. 2008; 15(6):1717-22. [PubMed: 18266040]

14. Weiser MR, Montgomery LL, Susnik B, Tan LK, Borgen PI, Cody HS. Is routine intraoperative frozen-section examination of sentinel lymph nodes in breast cancer worthwhile? Ann Surg Oncol. 2000; 7(9):651-5. [PubMed: 11034241] 
15. Cancer, AJCo. [cited 2018 November] AJCC cancer staging manual breast cancer. 7https:// cancerstaging.org/references-tools/quickreferences/Documents/BreastMedium.pdf2009

16. Galimberti V, Cole BF, Zurrida S, Viale G, Luini A, Veronesi P, Baratella P, et al. Axillary dissection versus no axillary dissection in patients with sentinel-node micrometastases (IBCSG 23-01): a phase 3 randomised controlled trial. Lancet Oncol. 2013; 14(4):297-305. [PubMed: 23491275]

17. Giuliano AE, Ballman KV, McCall L, Beitsch PD, Brennan MB, Kelemen PR, Ollila DW, et al. Effect of Axillary Dissection vs No Axillary Dissection on 10-Year Overall Survival Among Women With Invasive Breast Cancer and Sentinel Node Metastasis: The ACOSOG Z0011 (Alliance) Randomized Clinical Trial. Jama. 2017; 318(10):918-26. [PubMed: 28898379]

18. Network, NCC. Clinical Practice Guidelines Oncology - Breast Cancer (Version 2.2017). Jul 24. 20172017 Available from: https://www.nccn.org/professionals/physician_gls/pdf/breast.pdf

19. Gimbergues P, Dauplat MM, Durando X, Abrial C, Le Bouedec G, Mouret-Reynier MA, Cachin F, et al. Intraoperative imprint cytology examination of sentinel lymph nodes after neoadjuvant chemotherapy in breast cancer patients. Ann Surg Oncol. 2010; 17(8):2132-7. [PubMed: 20155400]

20. Espinosa-Bravo M, Navarro-Cecilia J, Ramos Boyero M, Diaz-Botero S, Duenas Rodriguez B, Luque Lopez C, Ramos Grande T, et al. Intraoperative assessment of sentinel lymph node by onestep nucleic acid amplification in breast cancer patients after neoadjuvant treatment reduces the need for a second surgery for axillary lymph node dissection. Breast. 2017; 31:40-5. [PubMed: 27810698]

21. Donker M, Slaets L, van Tienhoven G, Rutgers EJ. Axillary lymph node dissection versus axillary radiotherapy in patients with a positive sentinel node: the AMAROS trial. Ned Tijdschr Geneeskd. 2015; 159:A9302. [PubMed: 26488192]

22. Galimberti V, Ribeiro Fontana SK, Maisonneuve P, Steccanella F, Vento AR, Intra M, Naninato P, et al. Sentinel node biopsy after neoadjuvant treatment in breast cancer: Five-year follow-up of patients with clinically node-negative or node-positive disease before treatment. Eur J Surg Oncol. 2016; 42(3):361-8. [PubMed: 26746091]

23. Jeruss JS, Newman LA, Ayers GD, Cristofanilli M, Broglio KR, Meric-Bernstam F, Yi M, et al. Factors predicting additional disease in the axilla in patients with positive sentinel lymph nodes after neoadjuvant chemotherapy. Cancer. 2008; 112(12):2646-54. [PubMed: 18442039]

24. Zetterlund LH, Frisell J, Zouzos A, Axelsson R, Hatschek T, de Boniface J, Celebioglu F. Swedish prospective multicenter trial evaluating sentinel lymph node biopsy after neoadjuvant systemic therapy in clinically node-positive breast cancer. Breast Cancer Res Treat. 2017; 163(1):103-10. [PubMed: 28224384]

25. Kantor O, Pesce C, Liederbach E, Wang CH, Winchester DJ, Yao K. Are the ACOSOG Z0011 Trial Findings Being Applied to Breast Cancer Patients Undergoing Neoadjuvant Chemotherapy? Breast J. 2017; 23(5):554-62. [PubMed: 28295828]

26. Giuliano AE, Hunt KK, Ballman KV, Beitsch PD, Whitworth PW, Blumencranz PW, Leitch AM, et al. Axillary dissection vs no axillary dissection in women with invasive breast cancer and sentinel node metastasis: a randomized clinical trial. Jama. 2011; 305(6):569-75. [PubMed: 21304082] 


\section{Size distribution of sentinel node metastasis}

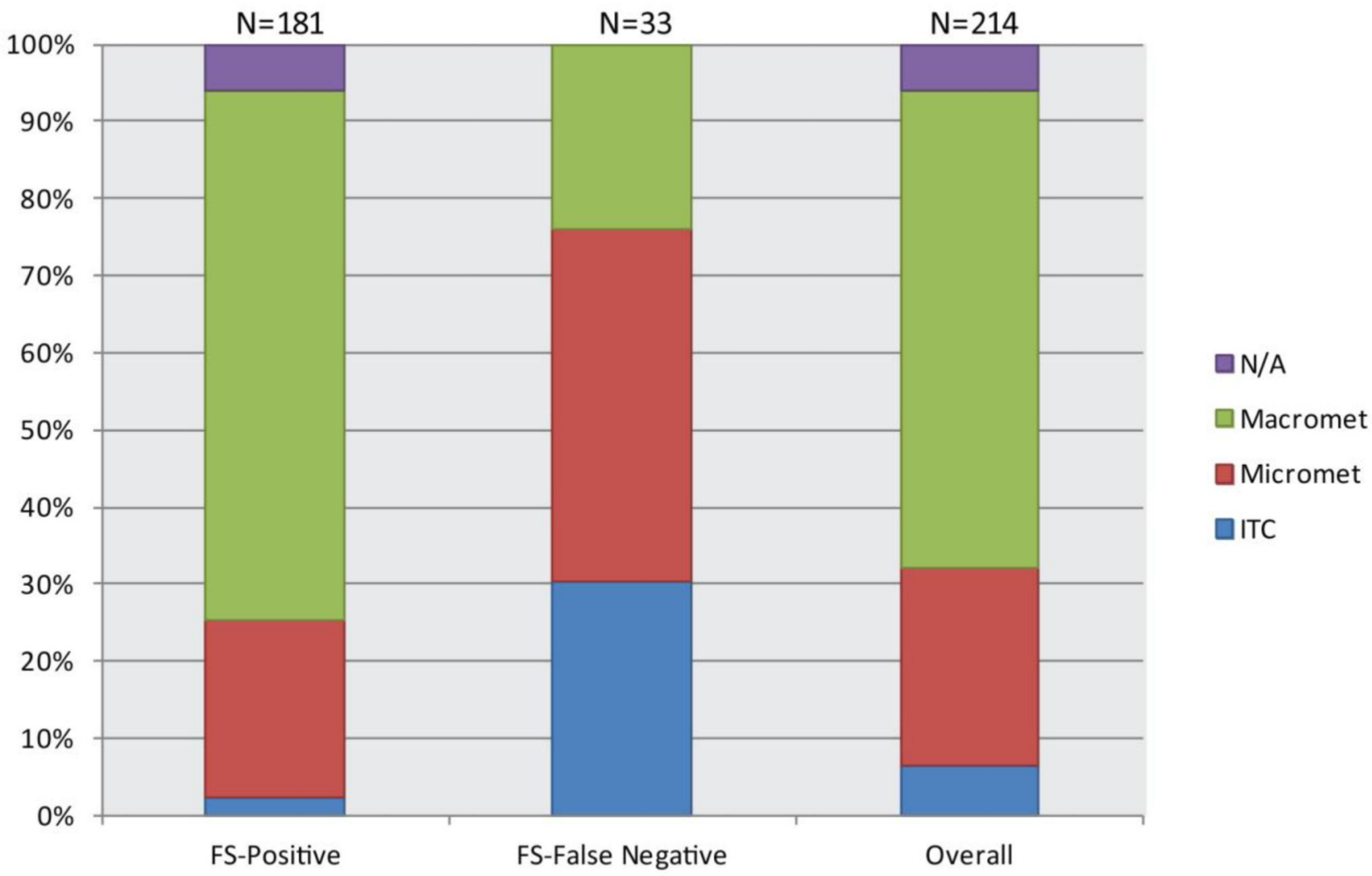

Fig. 1.

Comparison of sentinel lymph node metastases size based on detection by intraoperative frozen section.

N/A refers to cases in which sentinel node metastasis size was not reported.

ITC, isolated tumor cells 


\section{Frequency of additional positive non sentinel nodes on} completion axillary dissecton

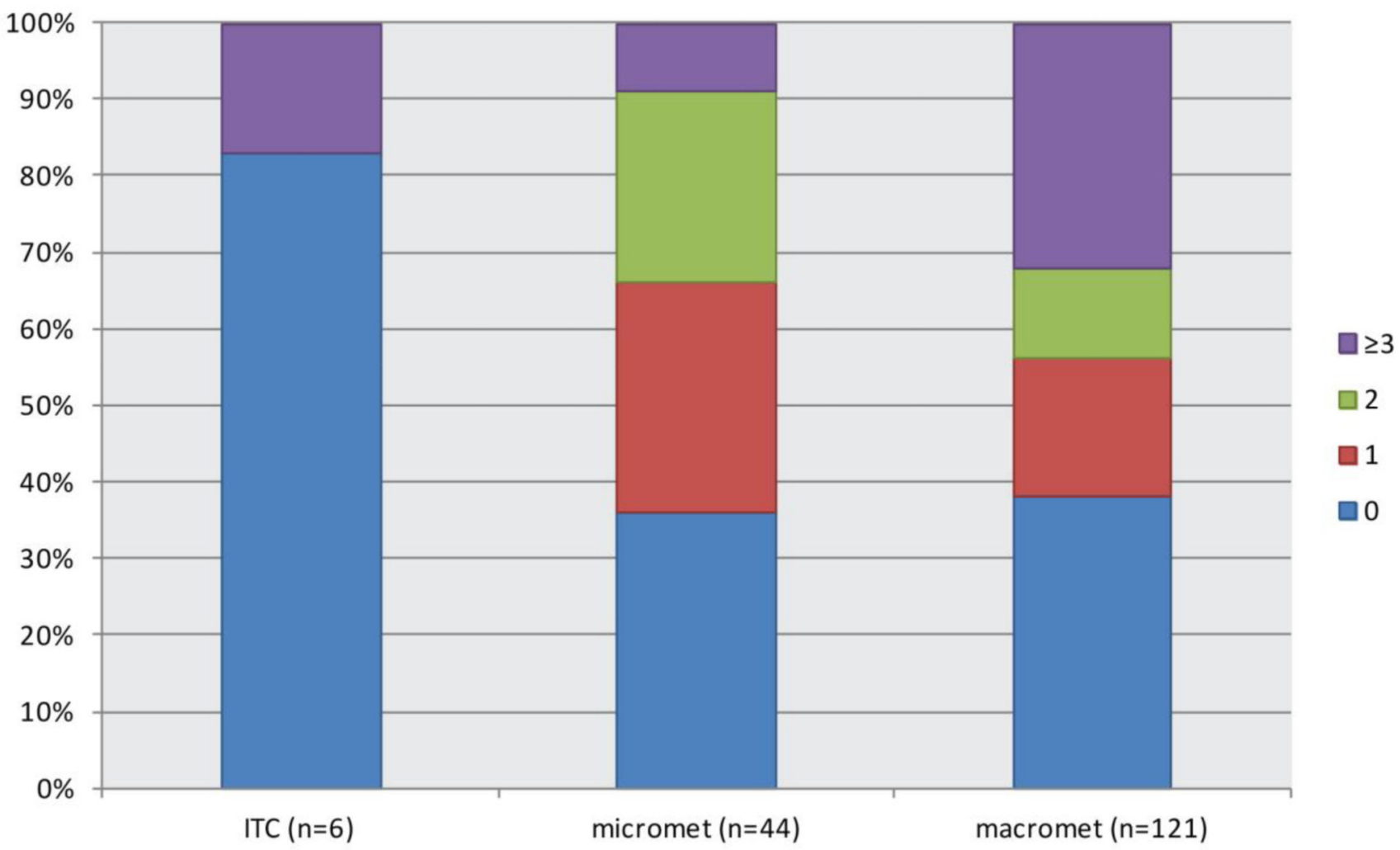

Fig. 2.

Overall frequency of additional positive non-sentinel nodes at completion axillary dissection based on SLN metastasis size.

SLN, sentinel lymph node; ITC, isolated tumor cells 
TABLE 1

Clinicopathologic characteristics of patients with positive sentinel nodes compared by frozen section result

\begin{tabular}{|c|c|c|c|c|}
\hline Variable & $\begin{array}{l}\text { Overall SLN positive } \\
(\mathrm{n}=214)\end{array}$ & $\begin{array}{l}\text { FS-False negative } \\
(\mathbf{n}=\mathbf{3 3})\end{array}$ & $\begin{array}{l}\text { FS-Positive } \\
(\mathbf{n}=\mathbf{1 8 1})\end{array}$ & p-value \\
\hline Age (median, range) & $49(23-76)$ & $49(27-76)$ & $49(23-75)$ & 0.8 \\
\hline \multicolumn{5}{|l|}{ Tumor Type } \\
\hline Ductal & $182(85)$ & $26(79)$ & $156(86)$ & \\
\hline Lobular & $13(6)$ & $3(9)$ & $10(6)$ & \\
\hline \multirow[t]{2}{*}{ Other } & $19(9)$ & $4(12)$ & $15(8)$ & \\
\hline & & & & 0.5 \\
\hline \multicolumn{5}{|l|}{ Clinical Nodal Status } \\
\hline Negative & $57(27)$ & $16(49)$ & $41(23)$ & \\
\hline \multirow[t]{2}{*}{ Positive } & $157(73)$ & $17(51)$ & $140(77)$ & \\
\hline & & & & 0.004 \\
\hline \multicolumn{5}{|l|}{ Histologic Grade } \\
\hline I & $2(1)$ & $1(3)$ & $1(1)$ & \\
\hline II & $27(13)$ & $2(6)$ & $25(14)$ & \\
\hline III & $179(83)$ & $28(85)$ & $151(83)$ & \\
\hline \multirow[t]{2}{*}{ N/A } & $6(3)$ & $2(6)$ & $4(2)$ & \\
\hline & & & & 0.1 \\
\hline \multicolumn{5}{|l|}{$\mathbf{L V I}^{*}$} \\
\hline Negative & $84(39)$ & $19(58)$ & $65(36)$ & \\
\hline Positive & $110(52)$ & $12(36)$ & $98(54)$ & \\
\hline \multirow[t]{2}{*}{ N/A } & $20(9)$ & $2(6)$ & $18(10)$ & \\
\hline & & & & 0.04 \\
\hline \multicolumn{5}{|l|}{ Subtype } \\
\hline ER+ HER2- & $130(61)$ & $26(79)$ & $104(57)$ & \\
\hline ER+ HER2+ & $30(14)$ & $3(9)$ & $27(15)$ & \\
\hline ER- HER2+ & $8(4)$ & $1(3)$ & $7(4)$ & \\
\hline ER- HER2- & $46(21)$ & $3(9)$ & $43(24)$ & \\
\hline \multicolumn{5}{|c|}{ Residual Invasive Tumor Size } \\
\hline Tis & $2(1)$ & 0 & $2(1)$ & \\
\hline T1-2 & $166(78)$ & $27(82)$ & $139(77)$ & \\
\hline T3-4 & $21(9)$ & $3(9)$ & $18(10)$ & \\
\hline N/A & $25(12)$ & $3(9)$ & $22(12)$ & \\
\hline \multicolumn{5}{|c|}{ Number SLNs Removed } \\
\hline 1 & $13(6)$ & $2(6)$ & $11(6)$ & \\
\hline
\end{tabular}




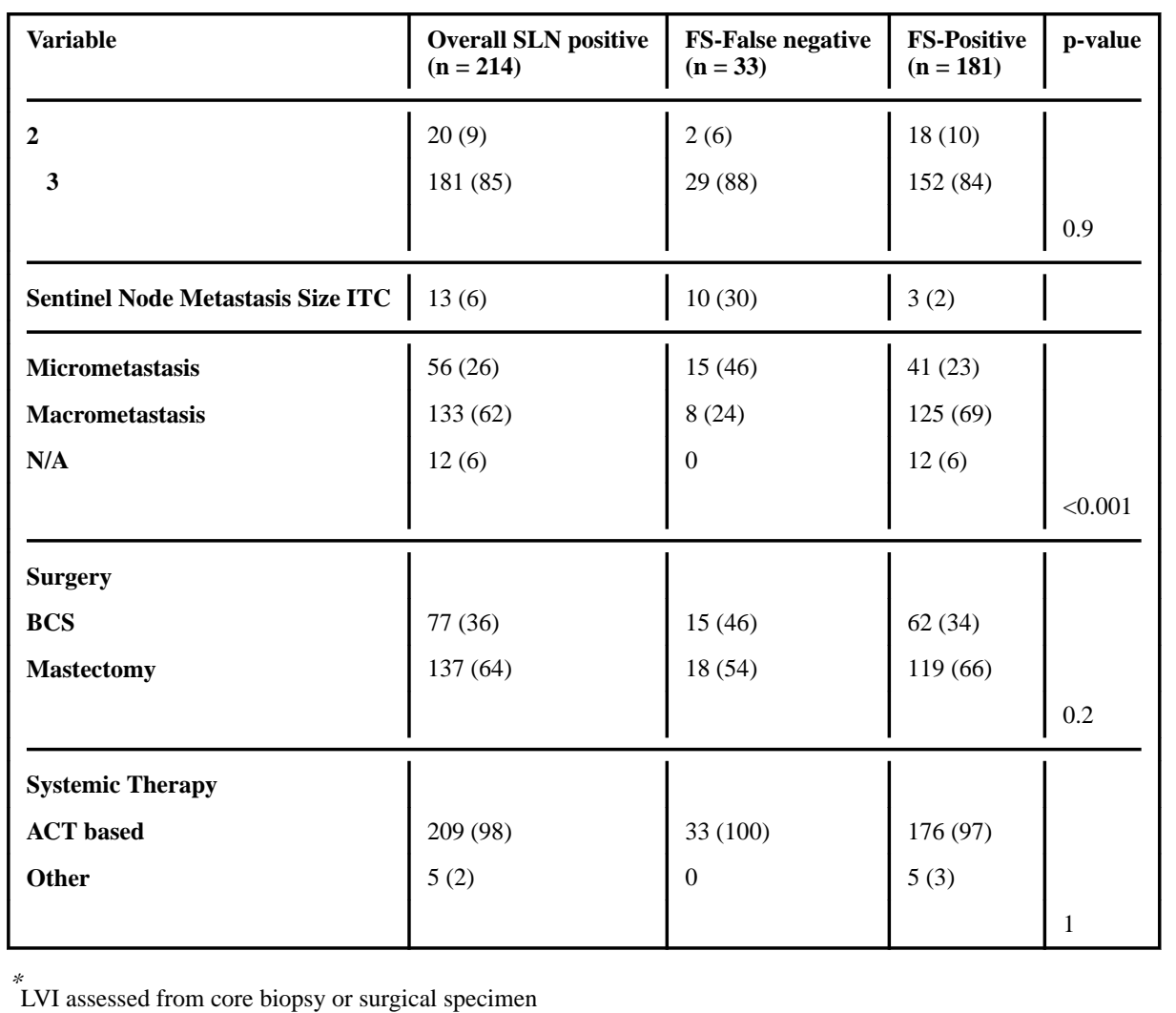

FS, frozen section; SLN, sentinel lymph node; LVI, lymphovascular invasion; N/A, not available; ER, estrogen receptor; ITC, isolated tumor cells; BCS, breast-conserving surgery; ACT, Adriamycin-cyclophosphamide and taxane 


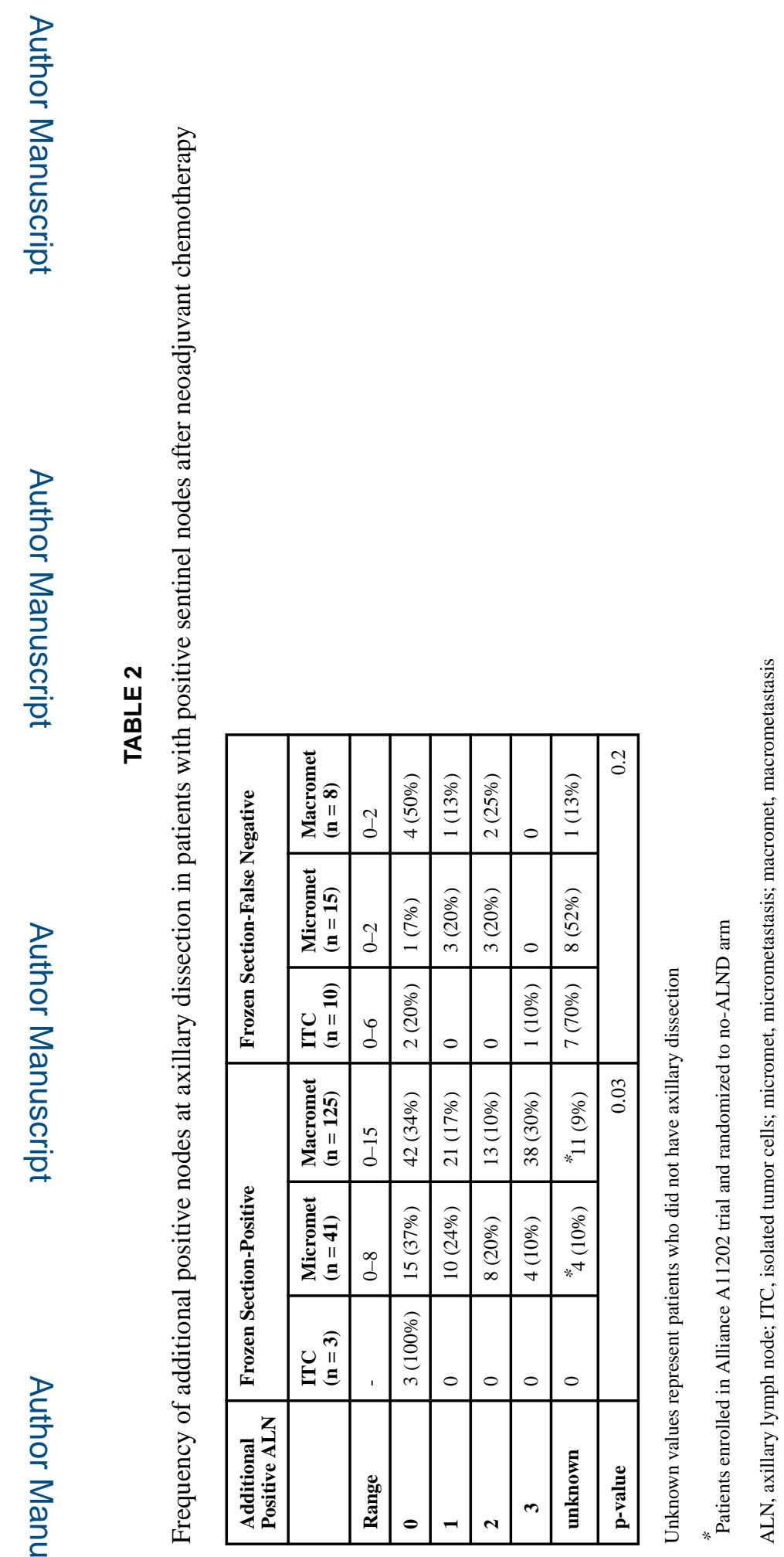

Ann Surg Oncol. Author manuscript; available in PMC 2019 June 01. 